\title{
La tradición joánica y su evolución. Un llamado a saber conjugar la fidelidad a Jesús con la creatividad del Espíritu en la Iglesia
}

\author{
Xavier Alegre, \\ Sant Cugat del Vallés, Barcelona, \\ Centro de Reflexión Teológica, San Salvador.
}

\section{Introducción}

La lectura del evangelio de Juan resulta siempre impactante. Invita a remontarse a las alturas de la visión de Dios sobre Jesús de Nazaret y sobre el mundo creado. No es, pues, casual, que en la tradición eclesial, sirviéndose del simbolismo de los cuatro animales de Ezequiel 1, 5-21 para representar a cada uno de los cuatro evangelistas, se escogiera precisamente el águila para este evangelio.

Pero, a la vez, una lectura atenta del evangelio puede resultar también inquietante. No sólo porque su lenguaje parece, a veces, repetitivo, monótono. Lo es, sobre todo, porque está formado por un montón de fragmentos, que si bien están unidos formando un puzzle maravilloso, a veces, sin embargo, parece que sus piezas han sido "mal encajadas". No es de extrañar, pues, que un gran especialista en Biblia, como fue R. Bultmann, se convirtiera en el campeón, discutible y discutido, en el arte de reencajar las piezas del "puzzle joanneo"'.

La tesis que voy a exponer aqui ${ }^{2}$ es que en la literatura joánica (evangelio y cartas) aparece un claro proceso de relectura de una tradición antigua, testimo-

1. Su comentario al evangelio de Juan sería el máximo exponente de este modo de acercarse al cuarto evangelio: Das Evangelium nach Johannes, Göttingen, 1941. La crítica no ha aceplado, con razón, las propuestas de Bultmann en favor de una descomposición del orden actual del evangelio y una recomposición. siguiendo sus critcrios personales.

2. Recojo aqul fundamentalmente lo que dije en una conferencia en la Universidad de Cantabria (España). en el curso 1998-1999. 
niada lundamentalmente en el evangelio de Juan y en la primera carta de Juan'. Unas relecturas que muestran que, gracias a la acción del Paráclito, las tradiciones venerables $\mathrm{e}$ incuestionables que se recogen (de algún modo se remontan a Jesús de Nazaret) no se han convertido en un fósil. Antes al contrario: la acción del Espíritu ha llevado a una actualización continua de la tradición: "cuando venga él, el Espíritu de la verdad, les guiará hasta la verdad completa", promete el Jesús de Juan en su discurso de despedida (ver 16, 13a).

Este fenómeno de la relectura de un texto no es nada raro en la Biblia. Lo encontramos, por ejemplo, en el pentateuco, en la obra del profeta Isaías (segundo y tercer Isaías), en la literatura paulina (la segunda carta a los Tesalonicenses reinterpreta 1 Tesalonicenses), en los evangelios sinópticos, etc. Conocer y tener en cuenta estas relecturas ayuda a interpretar adecuadamente los textos respectivos.

Por eso, vale la pena que nos preguntemos por qué se dan estas relecturas de la tradición "joánica" - y ello de un modo que ahora es detectable claramente en el texto del cuarto evangelio- y qué nos enseñan sobre las tradiciones de Jesús y sobre el signilicado del texto. A la vez, estas relecturas "canónicas" nos invilan a redescubrir la legitimidad y el valor de las actualizaciones o relecturas que las comunidades eclesiales vivas (pienso en algunas comunidades de base que he tenido la dicha de poder conocer un poco en El Salvador) siguen haciendo hoy por fidelidad a Jesús de Nazaret y por fidelidad a su Espíritu. Unas relecturas que pueden encontrar en Juan (y en el resto de los evangelios) unas pautas que les ayuden a hacer un auténtico proceso de discernimiento de su labor.

Por otro lado, pienso que una aproximación a través de los mismos textos joánicos a la historia que vivieron esas comunidades ayuda a orientarse en la lectura del evangelio y a comprender mejor el estado actual del texto y su significado.

\section{El cuarto evangelio, un enigma}

El evangelio de Juan (y en general, toda la literatura joánica) ha planteado siempre numerosos enigmas". Recordaré. fundamentalmente, cinco de ellos: (1)

3. Es lo que sostiene J. Zumstein en un interesante artículo, "Le processus de relecture dans la litterature johannique". Érudes Theologiques et Religeuses 73 (1998) pp. 161176. Como se ha hecho notar, incluso el título que se le dio, el de Euangelium kata locinnem. sería la última relectura del texto, en la etapa de la canonización del mismo: además de darle identidad, to asocia con los otros evangelios y lo sitúa -como evangelio único en varias formas (kata loannem) - bajo la autoridad de Juan.

4. Sobre las peculiaridades literarias y teológicas del evangelio de Juan puede verse ahora. con indicación de bibliografía en las cuestiones debatidas. J. O. Tuñf. "Evangelio según san Juan". en J. O.Tuñi - X. Alegre, Escritos joánicos y cartas católicas. Estella. 1995. pp. 13-172. 
¿quién es (o fueron) su(s) autor(es)?; (2) la relación del cuarto evangelio con los evangelios sinópticos; (3) el trasfondo religioso cultural de Juan; (4) la ubicación en la vida de Jesús de acontecimientos, como la expulsión de los cristianos de la sinagoga, algo que ocurrió ciertamente después de la muerte de Jesús e, incluso, de la caída de Jerusalén. Es lo que técnicamente, siguiendo a Gadamer, se ha denominado "la fusión de horizontes"; (5) diticultades que descubre la crílica literaria en el texto mismo. Como son muy conocidos y aceptados en la invesligación joánica, me limitaré a recordarlos someramente.

\subsection{El autor}

Un primer enigma lo plantea la cuestión, debatida desde la publicación de la obra, de quién fue el autor del evangelio. La tradición lo atribuyó muy pronto - no sin controversia, sin embargo- al apóstol Juan, identificado con el "discípulo amado", que desempeña un papel muy significativo en el cuarı evangelio. Otros. en cambio, lo atribuyeron al gnóstico Cerinto y recomendaron que este evangelio no se leyera.

El evangelio, de hecho, nunca afirma que fue escrito por el apóstol Juan. Ni siquiera en el capílulo 21 que, ciertamente, ha sido añadido por un discípulo del evangelista. Y este hecho resulta sorprendente. Sobre todo porque ya desde sus inicios fue un libro muy controvertido. Poder afirmar en el texlo que era obra de un apóstol hubiera zanjado definitivamente la cuestión de la autoridad y normatividad (la canonicidad o la "ortodoxia", diríamos hoy) del cuarto evangelio. Por lo menos esto es lo que hace Pablo cuando se le cuestiona su modo de actualizar "el evangelio de Dios" (cfr. Ga 1, 11-24; 1Co 9, I-2; 15, 8-1I). Por cllo, los mejores especialistas piensan hoy, a mi juicio con razón y sin distinción de confesiones cristianas, que el apósıol Juan no fue el autor del cuarto cvangelio. Más bien tenemos en Juan una obra conscientemente anónima:

... el verdadero garante de la autenticidad del testimonio es precisamente el Espíritu. Y, en este sentido, el Paráclito es el más profundo autor del evangelio de Juan. Porque es él quien ha desvelado el sentido de la tradición sobre Jesús. El es el verdadero intérprete de esta tradición. El que nos da su sentido y nos acerca verdaderamente a Jesús.

Con ello puede quedar claro que el anonimato de Juan no sólo no va en contra de la inspiración de la obra, más bien es una forma de subrayar, indirectametne, pero con firmeza y claridad, que es precisamente el Paráclito quien constituye la garantía última de la verdad del testimonio que tenemos en las páginas del evangelio de Juan. Este aspecto que, como tal, está com- 
pletamente abierto, no deja de constituir una enseñanza para nosotros y para nuestra lectura de Juans.

\subsection{La relación con los evangelios sinópticos ${ }^{6}$}

El enigma más sorprendente lo ha planteado, desde siempre, el hecho de que el cuarto evangelio sea tan distinto de los evangelios sinópticos, tanto en el lenguaje ${ }^{7}$ y marco geográfico-temporal", como en su teología que está, trinitariamente, mucho más desarrollada. Por otro lado, una escena como la purificación del templo (cfr. Mc 11, 12-25 par Mt y Lc), que en los sinópticos está situada en la semana en que Jesús murió, Juan la sitúa al comienzo de su vida pública (cfr. 2, 13-22). Si en los sinópticos (cfr. Mc 14, 12ss par) Jesús celebra la pascua con sus discípulos "el primer día de los ázimos, cuando se sacrificaba el cordero pascual" y muere a la hora nona del día siguiente ( $c f r$ Mc 13, 33-9 par), en el cuarto evangelio, Jesús es crucificado y muere el día de la preparación a la pascua (cfr. Jn 12, 28 y 19, 14), y a la hora sexta aún se encuentra en el pretorio (cfr. Jn 19, 14).

Sin embargo, y a pesar de todas estas diferencias, ya en el siglo II - lo sabemos por los Papiros 66 y 75 encontrados en Egiplo-, la obra recibió el tftulo de "evangelio", una palabra que no se encuentra (y lo mismo ocurre con el verbo "evangelizar") en toda la obra. Este título, como ya indiqué, sería la última relectura del texto, en la elapa de la canonización del mismo.

\section{El trasfondo religioso-cultural de Juan}

También la interpretación de Juan ha resultado, a menudo, un enigma, sobre todo cuando se ha querido determinar cuál es el trasfondo que ha condicionado

5. Tuñf, op. cit., p. 144. Sobre esta cuestión puede verse ibid., pp./41-144 y I56s (con bibliografía).

6. Sobre la relación de Juan con los sinópticos, cfr. D. M. Smith, "John and the Sinoptics: 'Some Dimensions of the Problem'". New Testament Studies 26 (1980) pp. $.425-444$.

7. Faltan palabras tan típicas como reino (sólo en Jn 3, 3.5), evangelio, predicar, parábola. conversión...y. en cambio, repite continuamente otras poco frecuentes en los sinópticos como vida, luz. camino, testimonio, verdad, conocer, los judíos. etc. Ver Tuñí, op. cil., pp. 19-23.

8. Si en LC 4. 19 se presupone que la vida pública de Jesús dura un año (de hecho los sinopticos sólo hablan de una pascua de Jesús), en Juan celebra tres pascuas: Jn 2. $13 ; 6,4 ; 11,55$. Y si en los sinópticos, la mayor parte de la vida pública discurte en Galilea, para luego encaminarse a Jerusalén y morir allí. al cabo de una semana de su entrada, en Juan las idas y venidas a Jerusalén son continuas y su estancia alli parece prolongada: en 1, 28 está en Betania; en 2. 1, en Caná de Galilea; en 2, 13, sube a Jerusalén; en 4, 3, vuelve a Galilea pasando por Samaria; en 5. I, sube a Jerusalén; en 6. I, vuelve a Galilea; en 7, 10, sube a Jerusalén y se queda alli hasta el final. 
su teología". Su trasfondo judeocristiano no se puede cuestionar hoy seriamen(c'". Pero otros posibles influjos —por ejemplo el de la gnosis- sí resultan controvertidos" . Con opiniones muy dispares, a veces contrapuestas. $\mathbf{R}$. Bulımann, por ejemplo, lo considera como un gnóstico convertido al cristianismo' ${ }^{12}$. Por ello afirma, por un lado:

La terminología y los conceptos gnósticos marcan, sobre todo, las palabras y discursos de Jesús, pero no se limitan, en absoluto. a la fuente de los "discursos de revelación", sino que recorren todo el evangelio y las cartas. Si el autor proviene del judaísmo, como lo demuesıran, quizás, las expresiones lingüísticas de rabinismo que encontramos con cierta frecuencia, proviene no de un círculo ortodoxo del judaísmo, sino de un judaísmo con tendencias gnósticas. Especialmente los medios literarios con los que construye las discusiones, el empleo de conceptos de doble significación y las expresiones que tienden a provocar una interpretación equivocada, delatan que vive dentro de un ambiente de pensamiento gnóstico-dualista. Porque tales significaciones ambiguas e interpretaciones equivocadas no son en absoluto únicamente medios técnicos formales, sino expresión de la visión fundamentalmente dualista: el revelador y el "mundo" no pueden entenderse; hablan lenguajes distintos $(8,43)$.

Pero, por otro lado, Bultmann"17 afirma también, con razón, que la encarnación de la Palabra, la historicidad del hombre concreto, Jesús de Nazaret separa claramente al autor del cuarto evangelio de la gnosis:

En el extremo opuesto, el polémico, pero muy sugerente, E. Käsemann Ilegó a escribir:

Apenas existe otro escrito en el nuevo testamento que haya irradiado tal fascinación dentro y fuera de la Iglesia a través de todos los siglos como el cuarto evangelio. Se encontró en él la auténtica voz de Cristo y se le deno-

9. Ver Tují, op. cit. pp. 149-153.

10. El comentario clásico del cuarto evangelio que destaca este aspecto es el de R. E. Brown, El evangelio según Juan (2 vol.), Madrid, 1980.

11. Uno de los grandes comentarios del evangelio, que más tiene en cuenta este posible trasfondo, sin llegar a la unilateralidad de las opiniones de Bultmann, es $\mathbf{R}$. Schnackenburg, El Evangelio según San Juan (4 vol.), Barcelona, 1980-1986. Para ver si y en qué medida las corrientes gnostizantes infuyeron en el cuarto evangelio, puede leerse: $X$. Alegre, "Evangelio según san Juan: un evangelio inculturado", Revista Biblica, 24 (1999) 23-32. Sobre las relaciones entre Juan y un escrito gnostizante, como el de las Odas de Salomón. ver X. Alegre, El concepio de salvación en las Odas de Salomón Contribución al estudio de una soteriología gnostizante y sus posibles relaciones con el cuarto evangelio, Münster, 1977.

12. Ver Teología del Nuevo Testamento, Salamanca, 1981, pp. 417-511.

13. Ibid., p. 457 ; $c f r$. pp. 458 y $484 s$. 
minó, a diferencia de los sinópticos, el evangelio espiritual, reconociendo así su misma pretensión. En su admisión en el canon está latente ciertamente una profunda ironía: apareció como celestial lo que no podía ya adscribirse a ningún lugar terreno. [...] su aceptación en el canon de la gran Iglesia tuvo lugar errore hominum et providentia Dei. Contra todas sus intenciones, la Iglesia aquí, seducida por la imagen del Dios Jesús que camina sobre la lierra, atribuyó a los apóstoles la voz fuera de aquí silenciada de aquellos que, una generación más tarde de nuestro evangelio, fueron condenados como herejes't.

De hecho, en los primeros siglos, el evangelio fue controvertido, sobre todo porque tue el evangelio que escogieron los grupos gnósticos que se separaron de las grandes iglesias para defender su interpretación de la fe. Pero, en contra de la opinión de Käsemann, pienso que las grandes iglesias cristianas acertaron plenamente al considerar como "nomativo para toda fe cristiana", es decir, "canónico", este evangelio. Comparto la opinión de Brown", cuando afirma:

El cuarto evangelio es diferente de los demás evangelios en su presentación cle Jesús y asombrosamente diferente de las cartas pastorales y de los Hechos de los apóstoles en su visión de las realidades eclesiales, de manera que los estudiosos han elahorado la teoría de que la comunidad cristiana de Juan podía haber sido un fenómeno sectario "marginal". Espero demostrar que no lue algo "Inarginal", sino más bien algo inserto en la corriente de confrontación aguda con las sinagogas y con otras iglesias y que, a pesar de las tendencias sectarias, todavía rezaba por la unidad con los demás cristianos. Pero lue un grupo cristiano retadoramente diferente y fugaz, tan pasajero, que estaba destinado a ser absorbido en los movimientos cristianos más amplios (a la derecha o a la izquierda) quc surgieron a partir del siglo I.

\subsection{El enigma de la "fusión de horizontes"}

El evangelio de Juan sitúa en la vida de Jesús acontecimientos que, como la expulsión de los cristianos de la sinagoga judía (cfr. 9.22; 12.42), acontecieron hastantc Jespués de la resurrección de Jesús. Tuñjits saca de ello (y de las caracicrística literarias, en gencral, que son propias del cuarto evangelio), la siguiente conclusión:

El evangelio de Juan es el resultado de una profunda relectura de la vida tcrrena de Jesús a lia luz del Espíritu. Y, al mismo tiempo, cs un reflejo de la vida de la comunidad en que se escribe. Este doble momento, que ha queda-

14. El testamento de Jesuis. El higal histórico del evongelio de Juan. Salamanca. 1983. pp. 106s.

15. Le commonidad del discipulo anado. pp. IOs.

16. Jessis y al evangetio sen la comumidad juánica, Salamanca, 1987, p. 64. 
do ampliamente expuesto en este capítulo, está fundido en un único texto. El texto del evangelio de Juan resulta, por tanto, de una densidad extraordinaria.

Y retiriéndose al texto final escrito que ha llegado hasta nosotros, añade ${ }^{17}$ :

$Y$ en este único texto es donde encontramos fundidos dos horizontes bien diferenciados: el de la historia de Jesús y el de la historia de la comunidad. Pero al fusionarse estos dos niveles de hecho constituyen como un tercer horizonte, fruto de la fusión de los otros dos. Es esta novedad, fruto de la mutua luz de los dos niveles fundidos, lo que constituye la aportación más original de esta obra.

\subsection{Los enigmas de la crítica literaria}

Un último enigma lo ha planteado, desde antiguo, la crítica literaria' ${ }^{14}$. Pues ella ha mostrado que detrás del texto de Juan se debe presuponer una larga historia de la formación de la obra, que ha dejado unas huellas imborrables en el texto actual. Este aspecto lo desarrollaré en el bloque siguiente.

\section{La crítica literaria, clave de acceso a la historia de la tradición joánica}

\subsection{Los dos finales del cuarto evangelio}

El ejemplo más claro —y señalado desde hace tiempo — de que detrás de la redacción del cuarto evangelio hay toda una historia, lo encontramos en el hecho de que Juan tiene, propiamente, dos finales. El primero, que sería el más antiguo y original, lo encontramos en Juan 20,30-31:

Jesús hizo en presencia de sus discípulos muchos más signos de los que han sido recogidos en este libro. Estos han sido narrados para que crean que Jesús es el Mesías, el Hijo de Dios; y para que, creyendo, y gracias a él, lengan vida elerna.

Se trata claramente del final original de la obra. Pero, a continuación, y de modo abrupto (y con un lenguaje literario un poco distinto del que hemos encontrado hasta ahora), la narración continúa asf: "Poco después Jesús se apareció otra vez..." (21, 1a).

Este nuevo comienzo, evidentemente, sorprende en este lugar. Por otro lado, cs obvio que el capítulo 21 fue escrito por un discípulo del evangelista. Pues en Juan 21, 22-23 se presupone la muerte del discípulo amado, presunto autor del evangelio. Esto es lo que implica la respuesta de Jesús a la pregunta que Pedro

17. Ihid. . p. 96.

18. Cfr: Tuñi. Evangelio. pp. 58s. 
le plantea: "Señor, ¿y éste [se refiere al discípulo amado] qué?". Jesús le responde: "Si yo quiero que él permanezca hasta que yo vuelva, a ti, $i q u e ́$ ? Tú, sígueme". Y añade el comentarista: "Estas palabras dieron pie para que circulase el rumor de que este discípulo no iba a morir. Sin embargo, Jesús no había dicho a Pedro que aquel discípulo no moriría, sino: ' $\mathrm{Si}$ yo quiero que él permanezca hasla que yo vuelva, a ti, ¿qué?'”. El fragmento concluye, entonces, con estas palabras:

Este discípulo es el mismo que da testimonio de todas estas cosas y las ha escrito. Y nosotros sabemos que dice la verdad. Jesús hizo muchas más cosas. Si se quisieran recordar una por una, pienso que ni en el mundo entero cabrian los libros que podrían escribirse $(21,24-25)^{14}$.

Un linal, por otro lado, que recuerda, por su estilo, el comienzo de 1Juan:

Lo que existía desde el principio, lo que hemos oído, lo que hemos visto con nuesiros ojos, lo que hemos contemplado y han tocado nuestras manos acerca de la palabra de vida - pues la vida se manifestó y nosotros la hemos visto y damos testimonio, y les anunciamos la vida eterna que estaba junto al Padre y se nos manifestó-, lo que hemos visto y oído se lo anunciamos para que también ustedes estén en comunión con nosotros. Nosotros estamos en comunión con el Padre y con su Hijo, Jesucristo. Les escribimos estas cosas para que su gozo sea completo $(1,1-4)$.

Ante este hecho, uno no puede menos de preguntarse varias cosas: ¿por qué hay ese doble final en Juan? ¿Por qué no se atrevió el discípulo que añadió el capílulo $21^{20}$ a incorporar simplemente esta última aparición del resucitado en

19. Según H. Thyen, "Entwicklungen innerhalb der johanneischen Theologie und Kirche im Spiegel von Joh 21 und der Lieblingsjüngertexte des Evangeliums", en M. de Jonge (ed.), L'Évangile de Jean. Sources, rédaction, théologie, Leuven. 1977. pp. 259-299. el capítulo 21 sería decisivo para poder comprender a Juan (no es un incro epílogo, sino la clave para poder entenderlo).

20. J. Zumstein. "La rédaction finale de l'évangile selon Jean "à l'exemple du chapitre 2 ]". en J. D. Käsıli, J.-M. Poffet y J. Zumstein (ed.), La communauté johannique et son histoire. La trajectoire de l'évangile de Jean aux deux premiers siècles. Genc̀ve: Labor et Fides, 1990. pp. 215-219 indica las razones que prueban que este capítulo es un añadido de un grupo de la escuela joánica al evangelio ya constituido. Da cinco I) el final 20,30-31, que presupone que el libro está completo (en esse libro): 2) el macarismo de 20, 29 tiene el papel de clausurar el círculo de las apariciones y dicta la regla que prevalecerá en la época postpascual; 3) hay una tensión irreductible entre la aparición de 20, 19-23 y la del capítulo 21. Si la aparición a los once enviaba a los discípulos a la misión por el don del Espíritu, resulta extraño que luego estén pescando. Por olro lado. el capítulo 21 es una leyenda de reconocimiento que suele presuponer que el que se aparece se da a conocer por primera vez. Y la reconciliación con Pedro, en 21, 15-19. resulta extraña después de la aparición a los once en 20. 19-23. pues allí se le olorgó ya el perdón; 4) el 
Galilea al resto de las apariciones del capítulo 20 ? ¿Qué relación hay entre el "evangelista" y el (¿los?) redactor(es) final(es)??21 Y, por último, ¿qué relación hay entre el cuarto evangelio y las cartas de Juan?

Para avanzar en la respuesta, que nos llevará a intentar descubrir la historia de la tradición joánica, conviene notar que, además del capítulo 21 , hay otros textos en el cuarto evangelio que plantean problemas cuando se hace una análisis literario riguroso del mismo.

\subsection{Problemas de crítica textual en un texto que utiliza un lenguaje no joánico}

El episodio de la mujer adúltera que encontramos en Juan 8, 1-1 I —un texto de vocabulario y teología claramente sinópticos y que no todos los manuscritos sitúan en este lugar (resulta imposible hoy saber cuándo y por qué se introdujo este texto canónico precisamente en este lugar)- parece un texto introducido en el cuarto evangelio en una etapa ulterior a la redacción definitiva del cuarto cvangelio.

\subsection{Textos que inicialmente irian unidos y ahora están separados}

Llama la atención, por ejemplo, que Jesús en 14, 31 diga "Levántense. Vímonos de aquî", sin que, de hecho, se vayan hasta 18, 1 ("Terminados estos discursos, Jesús y sus discípulos salieron de alli"). En 2.5. clarificaré más este punto. También se ha hecho notar que el encadenamiento canónico de los capílulos 5-7 parece secundario: la logica narrativa pediría el siguiente orden: capítulos $4,6,5,7^{22}$.

\subsection{Textos que presentan tensiones entre ellos (iglosas clarificadoras?)}

Otros textos presentan una cierta tensión entre ellos, como 3, 22 (cfir 4, I), donde Juan dice que Jesús bautizaba, mientras que en 4,2 se corrige la afirma-

"nosotros" de 21, 24 es el "nosotros" colectivo de la escuela joánica (resulta un eco del "nosolros" de I, 14. Y 21. 20-23 presupone la muerle del discípulo anado. autor del evangelio); 5) en Juan 21 cambia la problemática y, en parte, cl estilo con respecto a Juan 1-20.

21. La lesis de R. Bultmann (en Das Evangelium des Johannes) de que el evangelista habría sido corregido - por su falta de ortodoxia- por un redacior eclesiástico linal, quien habría aniadido, por ejemplo (aparte de desordenar incomprensiblemente cl texto). los elementos sacramentales que encontramos ahora tanto en 6, 5I-58 (eucaristía) y en 3. 5 (mención del agua) como en 19,34b-35. Según él. también habría añadido los elementos de escatología de futuro para contrarrestar la escalología de presente ( $c f r .5 .28-29 ; 6.39 .40 .44 .54$ y 12, 48). Una tesis que hoy día no es accptada. con razón. por la mayoría de los especialistas.

22. Así Zumstein. Lu redaction, p. 207. 
ción, indicando que propiamente Jesús no bautizaba, sino que lo hacían sus discípulos. O textos como 6,53-54, donde leemos: "Yo les aseguro que si no comen la carne del Hijo del Hombre y no beben su sangre, no tendrán vida en ustedes. El que come mi carne y bebe mi sangre tiene vida eterna, y yo lo resucitaré el último día", mientras que en 6,63 se afirma: "El Espíritu es quien da la vida; la carne no sirve para nada". También se han señalado las tensiones entre los textos que presuponen una escatología de presente y aquellos que hablan de una escatología de futuro (por ejemplo, Juan 5,25 y 5, 28-29).

\subsection{Relecturas de tradiciones anteriores}

En los discursos de despedida, si se compara 13,31-14,41 con 16, 11-33, se cae en la cuenta, por la semejanza de su contenido, que parecen ser dos versiones distintas de un mismo discurso de despedida. Inicialmente, sin embargo, ambas versiones no irían unidas, pues de lo contrario no se entiende por qué Jesús en 16, 5 se queja de que los discípulos no le pregunten a dónde va, cuando en 13, 36 (cfr $14,2 s s$ ) Pedro se lo ha preguntado explícitamente. Por otro lado. en la primera versión del discurso $(13,31-14,31)$ se reflexiona sobre la marcha de Jesús más bien desde el punto de mira cristológico (la pregunta fundamental es " $a$ a dónde vas?"), mientras que en la segunda versión $(15,4 b-33)$, la marcha de Jesús es releída desde la problemática antropológica y eclesiológica. Pues si bien la marcha de Jesús es necesaria y positiva para la comunidad, sin embargo, ésta se encuentra abandonada en un mundo hosti ${ }^{23}$.

También el gesto simbólico de Jesús, lavando los pies a sus discípulos (13. 1-5), refleja dos interpretaciones ${ }^{24}$. En la primera, 13, 6-11, y en profunda relación con el gesto de Jesús, el lavatorio de los pies es interpretado como gesto simbólico profético que anticipa el servicio radical de Jesús a sus discípulos hasta dar la vida por ellos. En cambio, en 13,12-17 parece ser una relectura del mismo hecho, pero ahora desde la perspectiva del ejemplo que da Jesús a sus discípulos para que aprendan a comportarse unos con otros como Jesús se comportó con ellos.

También el milagro de la curación del paralítico (5, 1-9a) da pie a dos relecturas, que profundizan en el significado del signo de Jesús. La primera la encontramos en 5, 9b-18 y ahonda aún más en el escándalo que provoca el hecho de que Jesús haya realizado el signo en sábado (una reflexión teológica que encontramos también en textos sinópticos como Marcos 3, 1-6 par y que refleja hechos escandalosos que realizó Jesús en su vida terrena) al alirmar el mismo Jesús, en lenguaje joánico, la identidad de su obrar con el del Padre, provocando así la oposición de los judlos $(5,18)$ :

23. Ibid., p. 173.

24. Cfr. J. O. Tuñí. El testimonio del evangelio de Juan, Salamanca, 1983, pp. 154157. 
Por eso los judíos trataban con mayor empeño de matarle, porque no sólo quebrantaba el sábado, sino que llamaba a Dios su propio Padre. haciéndose a sí mismo igual a Dios.

En una segunda relectura $(5,19-30)$, el milagro es prolundizado aún más. reflexionando sobre la obra y la autoridad del Hijo y su relación con cl Padre. Finalmente, en 5. 31-47 encontramos todo un discurso sobre los testimonios en lavor de Jesús, que muestran que es él y no sus adversarios quien liene razón en la controversia"*.

\subsection{La relectura de la Primera carta de Juan}

Por último, conviene notar que la Prinera carta de Juan ( $1 \mathrm{Jn}$ ) alude continuamente al cuarto evangelio. Pero lo hace con una problemática distinta de la Je aquél y, a veces, con una formulación también distinta, si bien el estilo y el lenguage de ambos escritos es muy semejante ${ }^{2 h}$.

De todo ello podemos sacar dos conclusiones claras: a) la hipótesis que mejor explica lo que nos ha revelado el análisis literario del cuarto cvangelio y de la primera carta de Juan es la existencia de una "escuela joánica", que estaría detrás de los textos en su estado actual (ello no excluyc quc el curto evangelio. como veremos, sea obra lundamentalmente del gran teólogo de esta escucla y comunidad) y b) la literatura joánica es un proceso de relectura continua de una tradición antigua.

3. La historia de las comunidades joánicas, clave de acceso a la historia de Ja tradición joánica y, o a las relecturas del texto evangélico

\subsection{Presupuesto}

La clave para orientarnos un poco dentro de lodos estos enigmas se encuentra en la historia de las comunidades joánicas. Su teología experimentó -como el cvangelio y las cartas lo atestiguan - una evolución, un crecimiento, a medida que los signos de los tiempos lo pidieron y los problemas de la comunidad lueron evolucionando. En todo caso, y con todos los matices que se quiera, tres son los momentos fundamentales de la tradición joánica: el de la tradición inicial del evangelio, el de su redacción definitiva y el de las cartas de Juan. En cste punto hay un consenso entre los especialistas ${ }^{27}$. Por ello, me parece acertada

25. Algo semejante podríamos decir también de la reinterpretación o releclura que hace Juan 2. 18-22 de la purificación del templo. que Jesús ha realizado en 2. 14-17: o de la reinterpretación eucarística $(6.51 \mathrm{c}-58)$ de la multiplicación de los panes (6. I. 15). que amplía la interpretación sapiencial que encontramos en 6, 22-5I b.

26. Cfr. Tuñí, Evangelio, p. I77s.

27. "L'évangile selon Jean n'est pas l'oeuvre d'une seule main. Deux, voire plusieurs rédateurs ont participé à l'élaboration du texte qui a ćté accueilli dans le canon 
la lesis de Zumstein"k, según la cual "el mismo texto se anuncia como un texto en devenir y que debe ser leído en su dinamismo interpretativo". Y su segunda tesis me parece también acerlada: "El medio en el cual se desarrolla este esfuerzo interpretativo - que se cristaliza en el crecimiento del texto- es la escuela joánica. Se trata, por tanto, de un medio estructurado y teológicamente coherente, cuya actividad consiste en transmitir, explicitar y actualizar la tradición en un espíritu de fidelidad a su fundador, el discípulo amado"2"

Con todo, conviene tener muy presente que el intentar reconstruir la tradición de las comunidades joánicas con ayuda de la historia de dichas comunidades exige una cierta modestia. Un conocedor tan excelente de la literatura joánica, como fue R. E. Brown, escribía en el prefacio de su csiudio de La comunidad del discípulo aniado:

Advierto al lector que mi reconstrucción reivindica, todo lo más, probabilidad; de tal forma que, si se acepta un sesenta por ciento de mis investigaciones, me daré por satisfecho. Por olra parte, en la reconstrucción de la historia de la comunidad, pienso centrarme en las relaciones con otros grupos y en una situación vital que refleja tanto amores como odios, y, por eso, este libro no es una teología joánica de conjunto con sus pros y sus contras netamente equilibrados ${ }^{\text {in. }}$.

\subsection{Los inicios de la tradición joánica}

Las tradiciones joánicas no son pura creación de la comunidad pospascual o de uno de sus geniales miembros. Como todos los evangelios canónicos, Juan se distingue también por querer recuperar para su comunidad la vida y la actuación de un hombre histórico, Jesús de Nazarel. Y todo parece indicar que se esfuerza por ser fiel a esta tradición "jesuánica". En este sentido, podemos atìrmar que a los inicios de la tradición joánica se encuentra la figura de Jesús de Nazarel. Todas las relecturas pretenden, ante todo, releer lo que fue y significó realmente

ncotestamentairc. Cette conviction s'inscrit dans la plupart des travaux qui jalonnent l'exégèse johannique contemporaine. C'est même -il convient de le noter- l'un des seuls points de consensus existant dans ce domaine de recherche si controversé" (Zumstein, La rédaction, p. 207).

28. La redaction, p. 213. La formulación la toma de $\mathbf{H}$. Weder.

29. La redaction. p. 213. Cfr. tambiên ldem. "La communauté johannique et son histoire", en Kästli-Poffet-Zumstein, I.c. p. 374. Sobre la escuela joánica cita R. A. Culpepper. The Johamine School. An Evaluation of the Johannine-School Hypothesis Based on an Investigation of the Nature of Ancients Schools, Missoula. MT. 1975.

30. L.c. p.I l. Sobre las reconstrucciones recientes de la tradición dentro de las comunidades joánicas, puede verse Zumstein, La redaction, pp. 210-214. El estudio más reciente sobre este tema es el de M. Hengel, Die johanneische Frage, Tübingen, Mohr. 1993. 
este personaje histórico. De ahí su interés por situar, de acuerdo con el principio que se ha denominado "fusión de horizontes", las relecturas de su palabra y de su obra en la vida de este personaje concreto. En este estadio no podemos excluir - pero tampoco podemos probar que haya sido así- que Juan el de Zebedeo haya podido jugar un papel en la transmisión de las tradiciones más antiguas. Esto explicaría mejor que ya muy pronto la tradición eclesial le atribuyera a él la obra. Pues sabemos, por Gálatas 2, 1-10, que el apóstol Juan fue un personaje significativo de la primera comunidad cristiana, la de Jerusalén ( $c f r$. también Hechos de los Apóstoles).

\subsection{El grupo inicial judío palestinense helenista}

El estrato más antiguo de la reinterpretación del cuarto evangelio proviene de unas tradiciones judeocristianas del sur de Palestina, quizás de Jerusalén. Ello explicaría el papel que desempeñan en este evangelio Jerusalén y las fiestas en el templo, así como el conocimiento de algunos lugares como la piscina de cinco columnas ( $c f r$, Jn 5, 2) o del "enlosado" (Lithostrotos), "que en la lengua de los judios se llama Gábbata" (Jn 19, 13). Discípulos de Juan Bautista (y de Qumran: eso explicaria, al menos en parte, la terminología dualista de muchos vocablos de Juan) formaron parte del grupo.

No todos los discípulos de Juan pasaron a Jesús. Por ello, debió haber una cierta tensión entre este grupo cristiano y los discípulos que siguieron fieles a Juan Bautista. Lo cual llevó al grupo cristiano a, sin negar el papel de Juan Bautista, reducir su papel a ser un mero testimonio en favor de Jesús (en los sinópticos, Juan tiene mayor relieve y una cierta independencia, aunque relativizada también en función de su interpretación cristiana como [mero] precursor de Jesús)".

La cristología propia de este estadio sería aún bastante sencilla y semejante a la de los sinóplicos: Jesús como Mesfas davídico, en quien se cumplían las profecias y quien se acredita por los signos (obras) extraordinarios que realiza y por su crítica y oposición a una determinada manera farisea de vivir la religión (oposición al sábado y al templo), lo cual le llevó a la pasión y a la cruz.

\subsection{La aportación samaritana}

Este grupo judeocristiano helenista se vio obligado a emigrar hacia el norte. Ignoramos por qué razones (podría ser por las persecuciones que sufrieron los

31. Como nota Brown, l.c., p. 160: "El cuarto evangelio niega perfectamente que JBap sea el Mesfas, Elias. el profeta, la luz o el novio. Insiste en que JBap debe decrecer. mientras que Jesús debe crecer. Sin embargo, a los adictos a JBap se les describc como personas que entienden mal a Jesús. aunque no le odian. Parece que existc una esperanza de su conversión". 
cristianos helcnistas. según Hechos 8, 1-3, o más tardc, cuando las amenazas judías a medida que se acercaba el momento de la insurrección contra los romanos se fueron haciendo más fuertes). En este proceso migratorio entrarían. al attravesar Samaria. en contacto - si es que no lo hicieron ya antes- con un grupo samaritano que pasó a tormar parte de la comunidad e influyó en su leología". Juan 4 sería un buen reflejo de este estadio. Quizás se deba a este grupo, además de una radicalización de la crítica del iemplo, la visión cristólogica de Jesús como el profeta definitivo anunciado por Moisés (cfr. De $18,15.18)$.

\subsection{La emigración a Siria}

Finalmente, el grupo se debió alīncar en Siria" ${ }^{32} \mathrm{Y}$ allí debió entrar en prolundo conllicto con la sinagoga judía. Un conflicto que habría vivido ya cuando Iuvo que emigrar de Palcstina.

\section{6. ¿Una últims emigración a Efeso?}

Algunos autores piensan que hay que ubicar a la comunidad joánica más hien en Eleso o que por lo menos tuvo que emigrar a esta ciudad, al final de su periplo. Por lo menos esto es lo que propone Zumstein ${ }^{\text {th: }}$

Nos parece que hay que mencionar una hipótesis que se discutc en la aclualidad: el cambio de situación que ha conducido a la redacción del capítulo 21 $y$, por tanto, el reencuadre del evangelio podría corresponder al desplazamiento del movimiento joánico de Siria a Asia Menor (Efeso). Implantado en un medio nuevo, el movimiento joánico sentiría la necesidad, a la vez, de anudar los lazos con la Iglesia del entorno (la "gran Iglesia", alimentada por la herencia paulina y la tradición sinóptica) y de legitimar su identidad.

32. Cfr: O. Cullmann. Der johanneische Kreis. Sein Platz in Spätjudentum, in der Jüngerschafl Jesu und in Urchristentum. Tübingen. 1975.

33. Cfr. Zumslein, La redaction, p. 226.

34. "Esta sugestión me la hizo en una conversación A. Lindemann, pero aparece también en B. Olsson. "The History of the Johannine Movement". Aspects on Johannine Liserature (Coniectanea Biblica. New Testament Series 18), Uppsala. Almqvist \& Wiksell International, 1987, p. 32. E. Ruckstuh!, por su partc, consiclera que el capítulo 21 debe situarse después de la redacción de las cartas joánicas y que constituye el último estadio que conocemos de la línea de desarrollo del joanismo. Su papel consistiría en acreditar el evangelio entre las comunidades de obediencia petrina cuando las comunidades joánicas están en vía de desaparecer, después de la crisis que han conocido ( $f f r .1 \mathrm{Jn})$, y los creyentes joánicos "ortodoxos" se agregan a la "gran Iglesia", y lo hacen queriendo conservar y encomiar su evangelio ( $c f r$. "Nachtrag zu den beiden vorausgehenden Aufsätzen". Jesus in Horizon' der Evangelien. Stuttgart: KBW 1988, p. 395-400)" (Zumstein. Lo redaction, p. 230, n. 52). 


\subsection{El contacto con la gnosis}

En un momento determinado de su historia - no se puede excluir que fuera relativamente pronto, pero también podría haberse acentuado este rasgo en Siria-, el grupo entró en contacto con ideas gnostizantes, procedentes, probahlemente, de una teología sapiencial judía como la de las Odas de Salomón, lo cual le permitió formular mejor, con ayuda de la personalidad del evangelista (la redacción final, Jn 21, 24-25, lo identifica con la figura "misteriosa" del "discí-

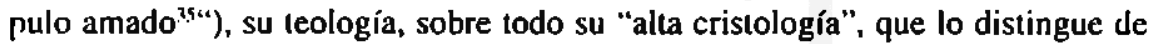
las comunidades petrinas.

Los discursos del evangelio - muy lípicos de la obra- reflejarían muy bien este estadio de la tradición. Temas como la preexistencia de Jesús y su divinidad se formularían quizás en este estadio. Con ello provocarían no sólo la reación de los judíos no cristianos, que considerarían esta teología como una auténtica provocación y blasfemia, ya que para ellos cuestionaría la fe monoteísta, sino incluso de algunos cristianos, tanto de la comunidad como fuera de ella, que verían como excesivas estas afimaciones cristológicas. Tanto más cuanto que ni siquiera las otras comunidades judeocristianas, lideradas por Pedro, habían llegado a este tipo de "alta cristología". Esto explicaría que los jetes judíos expulsaran a los cristianos joánicos de su sinagoga, provocando una auténtica crisis cn la misma comunidad.

Por otro lado, pienso que es en este estadio cuando los cristianos joánicos se abrieron más claramente a la entrada de los paganos (los "griegos") en la comunidad ( $c f r$. Jn 12, 20-26; la cruz ha posibilitado este acceso: cfr. Jn 12, 32s).

\subsection{Dos momentos especialmente críticos}

Dos acontecimientos muy graves marcaron la vida de esta comunidad y la(s) redaccion(es) del evangelio y de las cartas: la expulsión de la sinagoga judía ( $c f r: 9,22.34 ; 16,2$ y $12,42-43$ ) y el cisma de una parte de la comunidad que radicalizó su postura gnostizante, cuestionando la humanidad de Cristo y su Inuerte en la cruz ( $c f r$. I Jn).

35. No sería ni Juan ni uno de los doce, pues, dado lo controvertido del cuarto evangelio. su redacción tinal to hubiera indicado explícitamente. Sobre las diversas posibilidades de interpretación de esta figura controvertida, pucde verse R. Schnackengurg. E) Evangelio según san Jiuan, Barcelona, 1980. vol. I, pp. I04-133. pero teniendo en cucnta que el autor modificó su opinión en el vol. III de la obra. pp. 463-480; tamién D. Muñoz León, "¿Es el apóstol Juan el discípulo amado?”, Esıudios Biblicos 45 (1987). pp. 403-492: J. Kügler, Der Jïnger, den Jesus liebte. Literarische. theologische und historische Untersuchungen ar einer Schliasselgestah johnneische' Theologie und Geschichue. Stuttgart. 1988. 


\subsubsection{La expulsión de la sinagoga}

La expulsión de la sinagoga, cuando la comunidad ya estarfa en Siria, provocó una profunda crisis dentro de la misma comunidad. Pues, además de un profundo trauma religioso, provocaba también una marginación social, económica y política. A la dura tensión con la sinagoga judía habría contribuido, sin duda, la alta cristología a la que ha llegado la comunidad en este estadio con ayuda de la teología del "evangelista" (el "discípulo amado"). Este hecho queda claramente testimoniado en el cuarto evangelio, sobre todo en la conclusión de la primera parte:

A pesar de todo, fueron muchos, incluso entre los magistrados judíos, los que creyeron en Jesús. Sin embargo, no se atrevían a manifestarlo públicamente a causa de los fariseos, por miedo a ser expulsados de la sinagoga. Para ellos contaba más la buena reputación ante la gente que ante Dios (Jn $12,42-43 ; c f r .12,37-41 ; 9,22 ; 16,2)$.

Esle scría el problema fundamental de la comunidad en el momento en el cual el evangelista redacta su evangelio (Jn $1-20)^{36}$.

\subsubsection{Significado de Juan 21}

El hecho de que el redactor final de Juan no se atreviera a siluar adecuadamente el capítulo 21 en el marco del capítulo 20 es señal de que la obra estaba ya, en principio, concluida y que ella (y su autor, el discípulo amado) gozaba de tanta autoridad que no era posible retocarla en lo fundamental ${ }^{37}$. Para cl grupo, la "canonización" de Juan ha empezado. En este sentido, habría que situar al redactor más bien en la línea del evangelista y no en la del "corrector eclesial". Pues el "evangelista" goza de una autoridad de "visión" especial, superior incluso a la de Pedro (cfr. 20, 3-10; 13, 22-26 y 21, 7), del cual se reconoce en este capítulo su liderazgo dentro de las comunidades judeocristianas. Por otro lado, la situación que vive la comunidad en este momento debió ser más tranquila, lo cual le permitió ser más conciliadora con otras tendencias judeocristianas, como la representada por Pedro. Algunos retoques de la tcología lundamental del evangelista, como la escatología de futuro ( $c f r$. Jn 5 , 28-29) y los sacramentos (cfr. la alusión al bautismo en Jn 3. 5 o a la eucaristía en 6, 5 (c-58), no podemos excluir que hubieran sido añadidos en este momento. Pcro no como corrección, sino como clarificación de la teología del evangelista. En todo caso, hay un cierto reencuadre eclesial de las figuras de Pedro y del discípulo amado.

36. Cfr. Zunstein, La communauté, p. $368 \mathrm{~s}$.

37. Ast. con razón. Zumstein. La redaction, p. 219s. 


\subsubsection{Reencuadre de Pedro}

Es innegable que Juan 21 realiza un cierto reencuadre del evangelio $y$, por tanto, una relectura importante del evangelio. Este reencuadre se realiza:

a) Por el cambio de problemática: Juan 21 no se centra en la problemática cristológica, como Juan I-20, sino en la eclesiológica, motivada, en parte al menos, por la muerte, tanto del disć́pulo amado como de Pedro. Juan 21 "explicita las mediaciones por las cuales la obra del revelador continúa presente después de pascua. La cena eucarística de los vv. 12-13, la tarea pastoral de Pedro y el testimonio del discípulo amado son expresiones diversas de estas mediaciones pospascuales de la presencia de Cristo"3x.

b) Por el cambio de relación entre Pedro y el discípulo amado. Se reequilibra la relación: cada uno tiene su papel.

En Juan 13-20, el discípulo amado es el amigo íntimo de Jesús (en la última cena, según 13,23-25, Pedro necesita de él para averiguar quién es el discípulo que va a entregar a Jesús). Quizás sea también este discípulo el que en el patio del sumo sacerdote posibilita que Pedro pueda entrar en él (cfr. 18, 15-18). Es también el discípulo amado el que con María está al pie de la cruz (en contraposición a Pedro, que renegó de Jesús, según 18. 15-18.25-27) y al que se le conlía la madre de Jesús (como a la madre se le confía el discípulo como a Hijo: cfr. 19, 26-27). Es también el discípulo amado el primero que llega al sepulcro y a la le, aunque deja entrar primero a Pedro (cfr. 20, 2-10).

En cambio, en Juan 21 Pedro es el primer nombrado y líder del grupo (cfr. $2 \mathrm{l}, 2 \mathrm{~s})$. El es el que inmediatamente se arroja al agua al enterarse que el que se hal hecho presente en la orilla es el Señor (cfr. 21, 7). Como es Pedro también el que recibe el encargo de pastorear las ovejas de Jesús (cfr. 21, 15-17). Un encargo que es expresión del amor misericordioso y reconciliador del resucitado, quien le pregunta tres veces a Pedro, que antes le había negado tres veces, si lo ama más que los demás discípulos (cfr. 21, 15-17). Con ello, Juan 21 no habla de transmisión de "poderes basados en la autoridad" a Pedro, sino de un primado de Pedro que se ha de ejercer y manifestar en el amor. Pedro, que de su cuída ha aprendido a ser humilde, no se atreve a afirmar que lo ama más que los demás, sino, simplemente, que Jesús sabe que lo ama. A Pedro, pues, se le confiaría un "primado de liderazgo en la Iglesia", un primado que recuerda Iambién Pablo. en Gálatas 2, 7, cuando señala que a Pedro se le confió la misión entre los judíos y a él la misión entre los paganos.

Pero este hecho no quita que siga siendo verdad que el primero que ha reconocido al resucitado a la orilla del lago es el discípulo amado (cfr. 21, 7a). Pero ahora queda claro, a partir de Juan 21 , que tanto Pedro como el discípulo

38. Ibid. p. 222s. 
amado están en una relación de amor y de intimidad con Jesús. Los dos lo siguen ( $c f r .21,19.22$ y 21, 20). Los dos tienen una relación única, aunque distinta, con Cristo. En este sentido, en Juan 21, la figura de Pedro queda dignificada. Pues en el resto del evangelio ( $\mathrm{Jn}$ 1-20), Pedro, ni es el primer llamado, ni el primero en reconocer a Jesús (cfr. 1, 40-42). Ni es él el que hace la gran confesión de fe, sino Marta ( $c f r .6,69$ con 11, 27). No tiene una actitud adecuada en el lavatorio de los pies (cfr. 13,6-11) y pregunta intempestivamente sobre la suerte de Jesús (cfr. 13, 36-38). Y, para colmo, sólo corta una oreja en el momento del prendimiento (cfr. 18, 10-11), niega a Jesús (cfr. 18, 17 18.25-27) y no parece que esté al pie de la cruz (cfr. 19, 25-27) ${ }^{34}$.

\subsubsection{Reencuadre del discípulo amado}

También la figura del discípulo amado es resituada en este capítulo. En Juan 13-20, el discípulo amado aparecía en tres lugares clave del kerigma cristiano: a) en la últinua cena (cfr. 13,23-25: para su relación con Jesús se usa la misma lórmula que muestra la intimidad única entre Jesús y el Padre, en 1, 18; y si Jesús es revelador e intérprete del Padre, el discípulo amado es el testigo y el intérprele de Jesús delante de los suyos ${ }^{411}$ ); b) al pie de la cruz (es el tesligo eminente, representante de Cristo y fundador de Iglesia ${ }^{41}$ ); y c) en la tumba vacía (es el primero en llegar al lugar donde está en juego la revelación pascual y es el primero en conocer y llegar a la fe, independientemente de la escritura: cfr. el "todavía no conocían la escritura" de $\left.20,9^{42}\right)$. En este sentido, él es el lundador de una tradición que se impone tanto por su fiabilidad como por la perfección de su interpretación ${ }^{43}$. En él se daría, pues, un "primado del ver", ya que "ve más" incluso que Pedro (piénsese en la "alta cristología" que es patriinonio del discípulo amado).

En Juan 2l, la imagen cambia un poco. Sigue siendo el primero que reconoce al resucitado (cfr. 2I, 7) y es presentado como el que sigue al resucitado (Pedro es llaniado a este seguimiento: cfr. 21, 19.22). Pero ahora se plantea la cucstión de cuál es su papel después de su muerte y cuál es su rclación con Pedro, el pastor universal y mártir glorioso. Zumstein ${ }^{44}$ lormula así la respuesta:

Por un lado $-y$ esto no puede ser una coincidencia-, el destino y el lugar misterioso del discípulo amado para la época posipascual son anunciados por Cristo a Pedro. El discípulo amado toma, pues, rango al lado de Pedro y en

39. Cfr. Ibid., p. 224s.

40. Así ibid., p. 226s.

41. Así ibid.. p. 227.

42. Ibid.. p. 227.

43. Asi ibid.. p. 227s.

44. La communauré. p. 228. 
relación a Pedro en la historia de la Iglesia que comienza. Es integrado simbolicamente a los orígenes cristianos y designado en su diferencia. Por ouro lado, si no se impone ni por su función pastoral, ni por su martirio, el discípulo amado $-y$ el logion de Jesús se encuentra así verificado en un segundo grado- permanece, sin embargo, a pesar de su muerte. Permanece gracias a su testimonio (cfr. el juego de presentes en el v. 24). 21, 24 opera. en efecto, una gradación en el motivo del testigo: el discípulo amado no sólo es el testimonio verídico y, bajo este título, el iniciador de una tradición, sino también el artesano de una escritura. Esta escritura no es otra que el cuarto evangelio, que encarna la presencia pernanente del discípulo amado durante la época postpascual y que, por este hecho, se encuentra legitimada.

Con ello, el cuarto evangelio se convierte en un mensaje válido, no sólo para las comunidades joánicas, sino para todas las comunidades cristianas. De hecho, las comunidades jóánicas están viviendo, parece, un momento de cierta estabilización $n^{45}$.

\subsection{La relectura del Prólogo (Juan 1, 1-18)}

Otra relectura de la obra la ofrece también el Prólogo (Jn 1, 1-18). Un prólogo $^{46}$ dirige la lectura de la obra y la defiende contra la incomprensión y las interpretaciones erróneas que puedan hacerse de ellas. Aquí, el prólogo celebra, en el lenguaje del mito, la venida al mundo del logos preexistente y fija el cuadro hermenéutico dentro del cual debe ser leído el relato ( 1,1 forma inclusión con 20,28). Pone de manifiesto, ya desde el inicio de la obra, la radicalidad con la cual es afirmada la encarnación del Logos y su relación única con el Padre y con la creación. A la vez prepara lo que se dirá del significado del hombre Jesús en el resto del evangelio.

Al poner en relación al Logos con el comienzo absoluto y fundador y, después, al volver a trazar el movimiento que va desde la preexistencia a la encamación, el prólogo quiere llevar a pensar que el hombre Jesús que va a estar en el centro del relato que sigue es el desdoblamiento de Dios en el seno del mundo"?

De lo que hemos visto hasta ahora podemos concluir que el fenómeno de la relectura dentro del cuarto evangelio lo encontramos en diversos niveles" ${ }^{44}$.

Primero en las glosas, que clarifican algún punto del relato (Jesús no bautizaba personalmente: 4,1 ) o lo completan teológicamente (cfr. 4, 44; 7, 39b; 12,

45. Así ibid., p. 365).

46. Sigo a Zumstein, Le processus, p. 167ss.

47. Ibid., p. 169.

48. Cfr. lbid., pp. 170-174. 
16) o reencuadran algún aspecto tcológico (cfr. 5, 28s; 6, 39.40.44.54; 12, 48 ). Muestran el trabajo de la escuela a lo largo del tiempo.

En segundo lugar, encontramos también una relectura en aquellos textos que dan una segunda interpretación del relato que no cuestiona, sino completa, la primera. Así, por ejemplo 2, 18-22 completa 2, 14-17; 13, 12-17 relee 13, 6-11. El milagro de 5, 1-9a pone en marcha una cascada de relecturas que se encadenan: a) la controversia de 5, 9b-18; b) el discurso sobre la autoridad del Hijo (5. 19-30); c) el discurso sobre el testimonio $(5,31-47)$. Lo mismo podríamos decir de Juan 6 ó de los dos discursos de despedida $(13,31-14,31$ y 16, 4b-33, que recoge el anterior y lo relee ${ }^{44}$ ).

Pero no termina en el cuarto evangelio la historia de las relecturas que hace la comunidad joánica de la tradición evangélica. Pues hubo un hecho grave que obligó a la comunidad a escribir un texto que sirviera de relectura última de una obra completa, el cuarto evangelio, sin tocar ya el texto del mismo. Me refiero a la primera carta de Juan, como veremos en seguida.

El fundamento teológico de estas relecturas se encuentra para la escuela joánica" en 1) la necesidad de la memoria y 2 ) de su renovación perpelua ( $c f r$. Juan 2,$22 ; 12,16 ; 20,9$ ). Pero se trata de una memoria cuyo nacimiento está unido al acontecimiento de pascua. Ello significa que para la comunidad joánica el acontecimiento fundador no entrega por sí mismo lodo su significado. Por otro lado, la memoria va unida, según la escuela joánica, a la Escritura que la estructura e interpreta. Pero el agente de esta iluminación retrospectiva no es un hombre, ni siquiera el discípulo amado, sino el Paráclito. Por ello, los dos primeros dichos que se refieren al Paráclito en el cuarto evangelio $(14,16-17 ; 14$, 26) insisten en que el Paráclito es Cristo presente después de pascua y el artífice de la anámnesis comprehensiva de los logia de Cristo (cfr. también 15, 26). En cuanto a los dos dichos del segundo discurso (cfr. 16, 7-11 y 16, 13-15), ellos apuntan al presente $y$ al futuro que se abre.

\section{La segunda gran crisis: el cisma dentro de la comunidad y la primera carta de Juan}

La reacción negativa de los judíos y la consecuente persecución provocó una polarización dentro de la comunidad. A esta nueva situación debemos la existencia de la primera cartas". Por un lado, un grupo —que según 1Juan se separó de

49. Cfr. Ibid., pp. 170-174.

50. Cfr. Ibid., pp. 174-176.

51. La carta es posterior a Juan 21: así Zumstein. La communauté, p. 362; cfr. R. E. Brown, The Epistles of John. pp. 32-35 (Jn 21 no refleja aún la problemática dura de IJn, aunque es verdad que $\mathrm{Jn} 17$ insiste mucho en la unidad de la comunidad: pero eso vale también para una situación menos dura que la que encontramos en $\mathrm{IJn}$ ). 
la comunidad- quiso radicalizar tanto la divinidad de Jesús, que llegó a cuestionar su humanidad ${ }^{\$ 2}$ y el signilicado (expiatorio) de la cruz $^{53}$. Dentro de la misma comunidad, un discípulo del evangelista $\longrightarrow$ el autor de las cartas de Juan, que gozaba de un cierto liderazgo dentro de ella (aunque algunos, como Diotrefres lo cuestionan: cfr. 3Juan 9-10)- escribió, parece, una primera redacción de la primera carla - a modo de tesis- para clarificar las posturas.

Pero no logró convencer al grupo disidente, que acabó abandonando la comunidad. Entonces, "el anciano" (así se denomina a sí ınismo el autor en 2Juan I, I y 3Juan 1) realiza la edición final de JJuan, que se convirtió en pauta de lectura del evangelio y contribuyó eficazmente a que éste acabara siendo recibido como canónico dentro de las grandes iglesias.

La situación ahora es mucho más difícil que cuando se redactó Juan 21. Pues las dificultades no vienen de fuera, sino que ha habido un cisma interno:

Han oído que iba a venir un anticristo; pues bien, ya ha llegado: han surgido muchos anticristos. Esta es la prueba de que ha llegado la última hora. Salieron de entre nosotros, pero no eran de los nuestros. Porque si hubieran sido de los nuesiros, hubieran permanecido con nosotros. Pero asi ha quedado claro que no rodos son de los nuestros. Ustedes, en cambio, tienen el Espíritu que viene de Dios y lo saben todo. Les he escrito, no porque no conozcan la verdad, sino porque la conocen, y porque ninguna mentira procede de la verdad. ¿Quién es el mentiroso, sino el que niega que Jesús es el Mesías? Ese es el anticristo, el que niega al Padre y al Hijo. Todo el que niega al Hijo, se queda sin el Padre, y todo el que acepta al Hijo, tiene también al Padre. Ustedes deben permanecer fieles a lo que oyeron desde el principio. Si son fieles a lo que oyeron desde el principio, también ustedes permanecerán en el Hijo y en el Padre. Y ésta es la promesa que él nos ha hecho: la vida eterna. Les he escrito estas cosas teniendo delante a los que intentan seducirles (IJn 2, 18-26).

Por eso, el autor, aunque presenta lo que dice como repetición de la Iradición que conocen también los destinatarios ( $c f r .1,5 ; 3,11)$, y el prólogo alude al cvangelio (cfr. $1,1-4)$, sin embargo - y ello resulta sorprendente- jamás cita el

52. El presbítero dice a la comunidad: "En esto conocerán si poscen el Espíritu de Dios: si reconocen que Jesucristo es verdaderamente hombre. son de Dios; todo el que no reconoce así a Jesús, no es de Dios. Son más bien del anticristo. del cual han oído que tiene que venir, y ahora ya está en el mundo" (I Jn 4,2-3).

53. “QQuién es el que vence al mundo, sino el que cree que Jesús es el Hijo de Dios? Este es el que vino por agua y sangre, Jesucristo; no en agua únicamenle. sino en agua y sangre; y el Espíritu es el que da testimonio, porque el Espíritu es la verdad" ( IJn 5. 5-6). "Pero si caminamos en la luz como él, que está en la luz, estamos en comunión unos con otros, y la sangre de Jesús, su Hijo, nos purifica de lodo pecado $"\left(1 J_{n} I, 7\right)$. 
evangelio o hace relerencia al discípulo amado, que podrían garantizar su auloridad. La explicación más plausible está en el hecho de que también los adversarios reclamarfan para sí tanto el evangelio como la autoridad del discípulo amado $^{\text {s.4 }}$. A diferencia del evangelio, donde los adversarios principales eran los fariseos, aquí los adversarios parecen claramente gnostizantes".

En todo caso, el hecho de la canonización de Juan vendría confirmado por la existencia de IJuan, que utiliza un género literario distinto para clarificar algunas cuestiones que planteaba la interpretación del evangelio. La carta contrapone dos tipos de saber, es decir, el saber eclesial tradicional, que el autor incorpora con unas breves tesis introducidas por las fórmulas "nosotros sabemos", "nosotros hemos oído", y el saber heterodoxo, que es indicado con las fórmulas "el que dice" o "si decimos". Esto muestra que, en una situación de conflicto, la carta quiere ser una guía de leclura que permita tener acceso a la comprensión adecuada de la tradición ancestrals. Ello se ha hecho necesario por el conflicto grave existente en la comunidad sobre el modo como hay que interpretar algunas afirmaciones centrales del evangelio. Como señala Zumstein ${ }^{57}$ :

Este conflicto es el resultado tanto de la ambivalencia que caracteriza al cuarto evangelio mismo, como de las nuevas cuestiones suscitadas por la historia del movimiento joánico. Para mostrar cómo la tradición joánica debía ser comprendida, la escuela joánica ha compuesto una carta destinada a resolver las cuestiones en litigio y a ofrecer una guía de lectura que permita descodificar el evangelio. Esta proposición de relectura se esfuerza por reencuadrar las afirmaciones conocidas por todos y aceptadas por todos, es decir, el evangelio, haciendo referencia a lo que existía desde el comienzo. El supuesto inicio de la Iradición joánicast se convierte en el principio regulador de su interpretación y de su desartollo.

Al terminar su reflexión sobre la historia de las comunidades joánicas, Zumstein ${ }^{59}$ saca tres conclusiones: 1) el cristianismo joánico es un fenómeno antiguo (a nivel de tradición, tanto como lo es el paulino): 2) el evangelio es una obra en devenir (contiene varias relecturas), y 3 ) la alta cristología de Juan no es un fenómeno tardío.

54. Cfr. Zumstein, La communauté, p. 364.

55. Así ibid., p. 364. Según él, ibid. ,p. 368s, aunque Juan I-20 esté más marcado por el problema de la expulsión de la sinagoga, no podemos excluir que la tradición de Juan (por ejemplo, su lenguaje) no esté mareado por tendencias gnostizantes.

56. Asi, Zumstein. Le processus, p. 165. Por eso. la carta imita conscientemente al evangelio: empieza con un prólogo $(1,1-4)$, que recuerda el del evangelio, mientras que la conclusión (5. 13) es un eco del evangelio (20, 31). Ambos texios tienen un epílogo secundario ( $\mathrm{J} 21$ y $1 \mathrm{~J} \pi$ 5, 14-21).

57. Ibid., p. 167.

58. El ap arches de IJn I, I.

59. La communauté, p. 373. 


\section{Consecuencias para nuestra lectura creyente de la Biblia}

¿Qué lecciones podemos sacar de la historia de la comunidad joánica y de las continuas relecturas que fue haciendo a lo largo de su historia?

\subsection{Para ser fieles a la tradición hay que ser creadores, no meros repetido- res}

Esto es lo que hizo, programáticamente, tanto el evangelista, como la redacción eclesial del evangelio. Es verdad que, al intentar actualizar el evangelio, tanto inculturándolo como respondiendo a los retos que nos plantean los signos de los tiempos, la persona y la comunidad que lo haga se puede equivocar. Pero no puede hacer otra cosa si quiere ser fiel al Espíritu de Jesús. Pues si no lo hace, si se limita a repetir una tradición anquilosada, entonces es seguro que sí se equivocará.

\subsection{Nos enseña cuál fue y debe ser el fundamento teológico de toda relectura}

Podríamos resumirlo así: el fundamento teológico de toda relectura es la lidelidad creadora a Jesús de Nazaret y al Espíritu que nos guía en la relectura continua de la tradición.

\subsubsection{La fidelidad a Jesús de Nazaret}

A lo largo de la evolución de la tradición joánica hemos ido descubriendo la necesidad de "la memoria" que nos enraíza en el hecho inicial: la encarnación, la vida, la muerte y la resurrección de la Palabra encarnada en el hombre concreto que fue Jesús de Nazaret. Por ello fue esencial siempre para la comunidad joánica siluar sus enseñanzas en la vida concreta de Jesús, que lo llevó a la muerte y a la resurrección. Por ello situó sus tradiciones en el marco de lo que, desde Marcos, se ha denominado, con razón, evangelio (buena noticia). Para la comunidad joánica era esencial no convertir en mito la figura del crucificado. No se podía explicar quién era Jesús al margen de que fue un ajusticiado, una víctima de los poderes religiosos, civiles y económicos de este mundo. Había que mantener viva la memoria del "primer mártir" y "ponerla a producir", como suele decir Jon Sobrino, a proposito de los mártires salvadoreños - y de los mártires en general. Este aspecto ha sido recuperado maravillosamente por la teología de la liberación, dejándose guiar por un autor inspirado que fue eminente en este punto. Me refiero a Marcos ${ }^{\text {nf }}$.

60. Cfr. X. Alegre, "Marcos o la corrección de una ideología triunfalista. Pautas de lectura para un evangelio beligerante y comprometido", Revista Latinoamericana de Teología 2 (1985) pp. 229.263 
Pero no se trata de una memoria que se limite a recordar el pasado tan sólo desde la perspectiva positivista moderna de la historia del siglo pasado. Se trata más bien de una memoria que sabe descubrir, con los ojos de la fe, el significado más profundo de los hechos y las palabras de Jesús. Se trata, entonces, de una visión que no es accesible a los ojos de la came (como señalaba SaintExupery, "sólo se ve con el corazón; lo esencial es invisible a los ojos"), sino a los ojos de la fe. Porque la capacidad para comprender, a la luz de la Escritura sagrada (cfr. 20, 9; también 2,$22 ; 12,16$ ), lo que fue el personaje histórico y lo que sigue significando Jesús de Nazaret es don del resucitado a su comunidad. Es el resucitado el que capacita a sus ovejas para poder reconocer su voz (cfr. 20, 16 con 10,1-18). Y lo hace a través de su Espiritu (cfr. Juan 20, 22). Es el resucitado el que, desde el análisis de la nueva realidad, que ha empezado con la Pascua, nos envía al mundo ( $c f r$. Juan 20, 21) para reconciliarlo con Dios. Pero no desde una "gracia barata", como diría Bonhoeffer, sino invitando a la conversión. Pues en Juan, incluso después de la muerte de Jesús en la cruz, el perdón de los pecados no es automático. Y no lo será mientras vivamos en un mundo en el cual la fuerza del mal, simbolizada en Juan con la figura del demonio, que es mentiroso (cfr. Jn 8, 44cd), esclavizador ( $c f r$. Jn 8, 35) y asesino (cfr. Jn 8, 44ab), siga configurando unas estructuras que no permiten que el empobrecido y marginado pueda vivir.

Por ello, la experiencia pascual, con toda su graluidad, no sólo no excluye, sino que provoca el discernimiento continuo (la krisis: cfr. Jn 3, 14-2I) en la comunidad, según se acepte o no la propuesta de Jesús:

A quienes perdonen los pecados, les quedan perdonados; a quienes se los retengan, les quedan retenidos ( $\mathrm{Jn} 20,23)$.

Es también la recuperación de la enseñanza de Jesús de Nazarel, que dejó como testamento una consigna muy clara:

Les doy un mandato nuevo: que se amen los unos a los otros. Que, como yo les he amado, así se amen también ustedes los unos a los otros. En esto conocerán lodos que son mis discípulos: si se tienen amor los unos a los otros (Juan 13, 34-35).

Pero esta enseñanza ha sido, a menudo, mal interpretada, espiritualizando indebidamente este amor. Por esto, el autor de la primera carta de Juan se ve obligado a hacer una relectura de este texto y a clarificar este aspecto cuando escribe reflexiones como las siguientes:

Pues éste es el mensaje que han oído desde el principio: que nos amemos unos a otros. No como Caín, que, siendo del Maligno, mató a su hermano. Y ¿por qué lo mató? Porque sus obras eran malas, mientras que las de su hermano eran justas ( $\mathrm{Jn} 3,11-12$ ). Si alguno que posee bienes de la tierra ve a su hermano padecer necesidad y le cierra su corazón, ¿cómo puede 
permanecer en él el amor de Dios. Hijos míos, no amemos de palabra ni de boca, sino con obras y según la verdad (1Jn 3, 17-18). Si alguno dice: "amo a Dios" y aborrece a su hermano, es un mentiroso; pues quien no ama a su hermano, a quien ve, no puede amar a Dios a quien no ve. $Y$ hemos recibido de él este mandamiento: quien ama a Dios, ame también a su hermano ( $1 \mathrm{~J} n$ $4,20-21)$.

\subsubsection{La renovación continua de la tradición con la ayuda del Paráclito}

Para el evangelista, el Paráclito es el Cristo presente ahora, en la comunidad, después de la pascua. Y como tal, es el artífice, por un lado, de la memoria comprensiva de lo que lue Jesús de Nazaret (cfr Jn 14, 16-17). Pero, por el otro, es también el que va actualizando para la comunidad la vida y el mensaje de Jesús (cfr. Jn 14, 26).

A la vez, el Paráclito nos ayuda a preparar el futuro y a dinamizar la actuación y la reflexión creadora de la comunidad:

Pero yo les digo la verdad: les conviene que yo me vaya; porque si no me voy, no vendrá a ustedes el Paráclito; pero si me voy, se lo enviaré; y cuando él venga, convencerá al mundo en lo referente al pecado, en lo referente a la justicia y en lo referente al juicio; en lo referente al pecado, porque no creen en mí; en lo referente a la justicia, porque me voy al Padre, y ya no me verán; en lo referente al juicio, porque el Príncipe de este mundo está juzgado (Jn 16, 7-11). Cuando venga él, el Espíritu de la verdad, les guiará hasta la verdad completa; pues no hablará por su cuenta, sino que hablará lo que oiga, y les anunciará lo que ha de venir. El me dará gloria, porque recibirá de lo mío y se lo anunciará a ustedes. Todo lo que tiene el Padre es mío. Por eso he dicho: recibirá de lo mío y se lo anunciará a ustedes (Jn 16, 13-15).

Escribo estas líneas en El Salvador, en la casa en la cual fueron asesinados Ellacuría y demás compañeros, junto con Elba y Celina. Mártires de la fe y de la justicia. Víctimas de unos ídolos que deshumanizan y exigen víctimas. Estamos celebrando el vigésimo aniversario de Mons. Oscar Arnulfo Romero. Un "buen pastor", que supo comprender muy bien lo que significaban para la vida espiritual cristiana las relecturas de la tradición que proponía el cuarto evangelio. Por ello, desde una profunda experiencia de amor y unión con el Padre, desde el seguimiento radical de Jesús de Nazaret, el Hijo Unigénito del Padre (cfr. Jn I, 19) y con la ayuda del Espíritu que le llevó a escuchar y a acompañar a su pueblo empobrecido y masacrado, aprendió también él a dar la vida por sus ovejas, a ejemplo del buen pastor (cfr. Jn 10, II). Así se ha convertido, para esperanza de su pueblo y de todas las comunidades cristianas, en san Romero de América, como bellamente lo llama don Pedro Casaldáliga. 